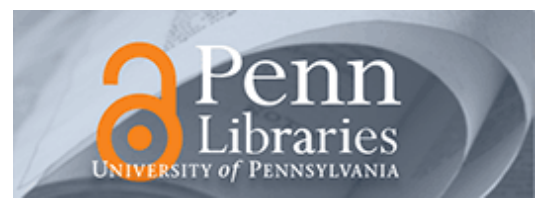

University of Pennsylvania

ScholarlyCommons

\title{
Stockpiling Anti-viral Drugs for a Pandemic: The Role of Manufacturer Reserve Programs
}

Joseph E. Harrington Jr

University of Pennsylvania

Edbert B. Hsu

Follow this and additional works at: https://repository.upenn.edu/bepp_papers

Part of the Business Commons, Economics Commons, and the Public Affairs, Public Policy and Public Administration Commons

\section{Recommended Citation}

Harrington, J. E., \& Hsu, E. B. (2010). Stockpiling Anti-viral Drugs for a Pandemic: The Role of Manufacturer Reserve Programs. Journal of Health Economics, 29 (3), 438-444. http://dx.doi.org/ 10.1016/j.jhealeco.2010.02.004

At the time of publication, author Joseph E. Harrington, Jr. was affiliated with Johns Hopkins University. Currently, he is a faculty member at the Business, Economics and Public Policy Department at the University of Pennsylvania.

This paper is posted at ScholarlyCommons. https://repository.upenn.edu/bepp_papers/29

For more information, please contact repository@pobox.upenn.edu. 


\title{
Stockpiling Anti-viral Drugs for a Pandemic: The Role of Manufacturer Reserve Programs
}

\author{
Abstract \\ To promote stockpiling of anti-viral drugs by non-government organizations such as hospitals, drug \\ manufacturers have introduced Manufacturer Reserve Programs which, for an annual fee, provide the \\ right to buy in the event of a severe outbreak of influenza. We show that these programs enhance drug \\ manufacturer profits but could either increase or decrease the amount of pre-pandemic stockpiling of \\ anti-viral drugs.

\section{Keywords} \\ pricing, pharmaceutical products, pandemic

\section{Disciplines} \\ Business | Economics | Public Affairs, Public Policy and Public Administration

\section{Comments} \\ At the time of publication, author Joseph E. Harrington, Jr. was affiliated with Johns Hopkins University. \\ Currently, he is a faculty member at the Business, Economics and Public Policy Department at the \\ University of Pennsylvania.
}




\title{
Stockpiling Anti-Viral Drugs for a Pandemic: The Role of Manufacturer Reserve Programs*
}

\author{
Joseph E. Harrington, Jr. \\ Department of Economics \\ Johns Hopkins University \\ 3400 N. Charles Street \\ Baltimore, MD 21218-2685 \\ 410-516-7615, -7600 (Fax) \\ joe.harrington@jhu.edu
}

\author{
Edbert B. Hsu, MD MPH \\ Office of Critical Event Preparedness and Response \\ Department of Emergency Medicine \\ Johns Hopkins University \\ 5801 Smith Avenue \\ Davis Bldg, Suite 3220 \\ Baltimore, MD 21209 \\ 410-735-6414, ehsu1@jhmi.edu
}

September 21, 2009; Revised February 11, 2010

\begin{abstract}
To promote stockpiling of anti-viral drugs by non-government organizations such as hospitals, drug manufacturers have introduced Manufacturer Reserve Programs which, for an annual fee, provide the right to buy in the event of a severe outbreak of influenza. We show that these programs enhance drug manufacturer profits but could either increase or decrease the amount of prepandemic stockpiling of anti-viral drugs.
\end{abstract}

\section{Introduction}

One of the available weapons for fighting pandemic influenza are anti-viral drugs. Currently, four antiviral medications - oseltamivir, zanamivir, amantadine, and rimantadine - are approved by the U.S. Food and Drug Administration for prevention and/or treatment of influenza. While the efficacy of particular drugs against novel influenza viruses during a pandemic remains uncertain, oseltamivir and zanamivir are the recommended first-line drugs of choice due to resistance patterns of known circulating viruses. Oseltamivir is sold as Tamiflu ${ }^{\circledR}$ by Hoffman-La Roche, while zanamivir is sold as Relenza ${ }^{\circledR}$ by GlaxoSmithKline.

Given the speed by which pandemic influenza can spread, if anti-viral drugs are to play a role in its curtailment, it will require adequate stockpiling of these drugs. For this purpose, the Center for Disease Control has accumulated millions of courses of anti-viral drugs in the Strategic National Stockpile. At the same time, private organizations - such as hospitals - are encouraged to form their own stockpiles. To

\footnotetext{
*The authors are grateful to the referees and the editor, Thomas McGuire, for their comments.
} 
reduce the upfront outlay to a customer, Hoffman-La Roche and GlaxoSmithKline have each recently developed a Manufacturer Reserve Program (MRP). Launched in June 2008, the Roche Antiviral Protection Program (RAPP) holds one course of Tamiflu in its inventory for an annual reserve fee (which is low relative to the purchase price of the drug). ${ }^{1}$ The holder of a RAPP contract has the right to buy a single course at the regular price with delivery within 24-48 hours. ${ }^{2}$ Thus, rather than immediately purchasing at the regular price to stockpile on its own, an organization can purchase the right to buy and thereby ensure supply. GlaxoSmithKline offers a similar program for Relenza ${ }^{\circledR}$, called Pandemic Readiness for Employers Program (PREP).

The objective of this paper is to analyze Manufacturer Reserve Programs with regards to their pricing and how they impact the incentives of the drug manufacturers to build inventories in preparation for pandemic influenza. A starting point to our analysis is that an unconstrained purely profit-maximizing drug company would significantly increase the price of its anti-viral drug in response to pandemic influenza, in order to extract some of the pandemic-induced surplus realized by consumers. However, both political and ethical concerns make such a pricing strategy unlikely; drug manufacturers would be subject to intense political pressure not to raise the price of anti-viral drugs in response to the societal calamity of a pandemic. Due to that political and ethical constraint, a drug manufacturer is limited in how much surplus it can extract through the pricing of the drug itself. We show that a Manufacturer Reserve Program is able to extract some of that surplus, though it is not as effective as being able to raise the drug price when there is a pandemic. A second and more important result is that Manufacturer Reserve Programs can either result in an increase or decrease of pre-pandemic stockpiling.

Related Literature There is a vast literature that explores pricing with demand uncertainty - both at the individual and aggregate level - but none that considers "right to buy" programs. ${ }^{3}$ In considering this literature, one can ask how firms and consumers could respond to demand uncertainty which reveals itself over time. One approach is to adjust price as agents learn about demand. Such price adjustment can also be a method for engaging in price discrimination when buyers are heterogeneous. This approach is examined in Courty and Li (2000) and Nolke and Peitz (2007). As we've argued that there are political and ethical constraints limiting the ability to raise price in response to a severe outbreak of influenza, the option of adjusting price over time is not available to a manufacturer of anti-viral drugs.

A second approach to handling demand uncertainty is to ex ante set different prices for different units. The optimality of such an approach is established in Dana (1999). A firm sets price before demand uncertainty is realized which, in our setting, corresponds to setting price before it is learned there is a pandemic. What a firm

\footnotetext{
${ }^{1}$ In the case of one hospital, the annual fee for RAPP was about $7.5 \%$ of the cost of buying the drug. The drug has a shelf life of about five years.

${ }^{2}$ Details on this plan can be found at <www.pandemictoolkit.com/tamiflusupplyordering/stockpiling-dilemma.aspx $>$.

${ }^{3}$ For a general survey, see Stole (2007). There is, of course, a huge finance literature on call options but that work is very different from what is considered here.
} 
does is to set multiple prices and limit how much supply is available at each price; for example, providing 10,000 units at a price of $\$ 50$ and 1,000,000 units at a price of $\$ 200$. In this way, a firm can effectively charge a higher price in response to a positive aggregate demand shock as the high priced units will only be bought in that demand state. We do not permit such a pricing mechanism in our model because it is equivalent to raising price in response to a severe outbreak, and therefore is likely to be construed as a violation of the political and ethical constraints mentioned above. It is true that there is a similarity between setting two different product prices - with units priced at the higher level only being purchased in the high demand state - and our mechanism of setting one product price and selling the right to buy - which a consumer exercises only in the high demand state. However, the pricing mechanisms are not equivalent because the right to buy is purchased before a consumer learns the demand state, while with the multi-price scheme consumers purchase after learning the demand state. In fact, we show that the right to buy does not extract surplus as effectively as setting different prices for different demand states.

\section{Model}

Assume there is one consumer type who, if having developed a need for an antiviral drug during a pandemic - either for prophylaxis or treatment - values the drug $\bar{v}^{4}$ The probability of a pandemic occurring is $\alpha$ and, in that event, the amount of need for the drug, denoted $\widetilde{q}$, is random - as it depends on the intensity of the pandemic - and distributed according to the twice differentiable cdf $F:[0,1] \rightarrow[0,1]$. Assume $F^{\prime}>0$, for all $\widetilde{q} \in[0,1]$. Normalizing the population mass to one, $\widetilde{q}$ is to be interpreted as the fraction of the population that demands the anti-viral drug in the event of a pandemic. The primary purpose for having pandemic severity be random is so that consumers, even if they know the inventory of the company, are uncertain about availability of supply when there is a pandemic.

The price that the manufacturer can anticipate receiving in the event of a pandemic is fixed at some level, denoted $p$. What is crucial for the ensuing analysis is that $p<\bar{v}$. The most natural motivation for this assumption is that the manufacturer anticipates some chance of being constrained in how much it can raise price should a pandemic occur. These constraints could be political - as the government limits how much the manufacturer can raise price in the face of a public health emergency - or ethical - as the manufacturer's executives conclude that the morally right decision is to sacrifice profit for the social good. Political constraints could take the form of price caps based on the Medicaid rate, possible prosecution for price gouging or "excessive pricing" (which is an antitrust violation in some countries), or pressure from elected officials (with the looming threat of price regulation). As long as there is some probability that price is constrained then the expected pandemic price will be less than

\footnotetext{
${ }^{4}$ While assuming a single type is done for simplicity, it also serves to distinguish the forces we identify from those that are due to consumer heterogeneity and have been identified in other papers dealing with demand uncertainty. For example, work on advance purchase discounts; see Gale and Holmes (1992, 1993) and Dana (1998).
} 
$\bar{v}$. To see why, first note that the optimal pre-pandemic price is naturally less than $\bar{v}$ because consumers value anti-viral drugs less when there is not a pandemic. In the event of a pandemic, the manufacturer will either raise price to $\bar{v}$ (if unconstrained) or price below $\bar{v}$ (if constrained). Hence, if $p$ is the expected pandemic price then surely $p<\bar{v}$.

To simplify the analysis, it is further assumed that the drug price is such that consumers do not find it optimal to stockpile. Thus, consumers will be choosing between buying into an MRP or waiting to purchase in the event of a pandemic. A sufficient condition for a consumer not to find it optimal to stockpile is ${ }^{5}$

$$
\bar{v} \alpha \int_{0}^{1} \widetilde{q} d F(\widetilde{q})-p<0
$$

This condition is not difficult to satisfy. For example, suppose the value of the drug to a consumer is $\$ 50$ with seasonal flu and $\$ 200$ with pandemic influenza. If the drug is priced to meet seasonal demand - in which case, $p=50$ - then this condition holds as long as the probability that a consumer will need the drug because of a pandemic is under 25\%. Consistent with this assumption is that MRPs have been introduced in an environment for which there is very little stockpiling by nongovernment organizations.

Due to production lags, the drug manufacturer decides on its supply prior to learning whether there is a pandemic. The marginal cost of producing the drug is constant at $c$. It is assumed that $\alpha p>c$ so the drug manufacturer finds it optimal to stockpile, which it may do on its own or in conjunction with an MRP. ${ }^{6}$

Though there are two actual manufacturers of anti-viral drugs, our model has only a single drug manufacturer and thus ignores the effects of competition. First note that these drugs are far from being perfect substitutes. Tamiflu ${ }^{\circledR}$ is easier to take than Relenza ${ }^{\circledR}$ as the latter must be inhaled which may make it problematic for young children or patients with chronic respiratory diseases. It may also be the case that these two drugs are complements in the event of a pandemic because of concerns that a virus may become drug-resistant. While competition is still a relevant feature of the market for anti-viral drugs, there are other important forces at work and our analysis focuses on some of them.

\footnotetext{
${ }^{5}$ This condition compares stockpiling to not buying the drug and is sufficient but not necessary as a consumer may choose not to stockpile because she prefers to wait and purchase it in the event of a pandemic or buy into an MRP.

${ }^{6}$ Note that we have assumed consumers do not find it optimal to stockpile while the manufacturer does. Even without assuming that the drug manufacturer has lower carrying cost of stockpiling due to scale economies (which would be a natural assumption), firm stockpiling is more efficient than consumer stockpiling because consumers cannot resell. Thus, a consumer may have a unit of the drug and, even if there is a pandemic, not need it; while if the drug manufacturer controls the unit then it can sell it to consumers who need it.
} 


\section{Benchmark Case: Producing without a Manufacturer Reserve Program}

Given the manufacturer prices its anti-viral drug at $p$ - both with and without a pandemic - let us first examine the optimal supply decision when a Manufacturer Reserve Program (MRP) is not used. Let $K$ denote the supply produced to deal with pandemic demand. The manufacturer's expected profit is

$$
\alpha p\left[\int_{0}^{K} \widetilde{q} d F(\widetilde{q})+\int_{K}^{1} K d F(\widetilde{q})\right]-c K .
$$

With probability $\alpha$, there is a pandemic of size $\widetilde{q}$. Given an inventory equal to $K$, if $\widetilde{q} \leq K$ then all pandemic demand can be met, which generates revenue of $p \widetilde{q}$. If $\widetilde{q}>K$ then demand outstrips supply in which case revenue is $p K$. is ${ }^{7}$

The manufacturer chooses $K$ to maximize (1). The first-order condition (FOC)

$$
\alpha p[1-F(K)]-c=0 .
$$

The marginal expected revenue from producing one more unit depends on the probability that the additional unit will be sold, $\alpha[1-F(K)]$, which equals the probability of a pandemic $\alpha$ times the probability that there is a shortage, which is $1-F(K)$. Solving the FOC, the optimal inventory in preparation for pandemic influenza is:

$$
K^{*} \equiv F^{-1}\left(\frac{\alpha p-c}{\alpha p}\right) .
$$

For purposes of comparison, consider the case when the manufacturer is able to raise price to $\bar{v}$ in response to pandemic influenza. Its expected profit is

$$
\alpha \bar{v}\left[\int_{0}^{K} \widetilde{q} d F(\widetilde{q})+\int_{K}^{1} K d F(\widetilde{q})\right]-c K,
$$

with FOC:

$$
\alpha \bar{v}[1-F(K)]-c=0
$$

The resulting optimal pre-pandemic inventory is

$$
K^{* *} \equiv F^{-1}\left(\frac{\alpha \bar{v}-c}{\alpha \bar{v}}\right) .
$$

In comparing supply in these two scenarios, the drug manufacturer supplies more when it is not prevented from increasing price in response to a pandemic (as long as $c>0)$ :

$$
K^{* *}>K^{*} \Leftrightarrow F^{-1}\left(\frac{\alpha \bar{v}-c}{\alpha \bar{v}}\right)>F^{-1}\left(\frac{\alpha p-c}{\alpha p}\right) \Leftrightarrow c \alpha(\bar{v}-p)>0 .
$$

As it can anticipate a higher price when there is pandemic influenza, the manufacturer optimally builds a larger inventory in preparing for it.

\footnotetext{
${ }^{7}$ The second-order condition is satisfied: $-\alpha p F^{\prime}(K)<0$.
} 


\section{Producing with a Manufacturer Reserve Program}

\subsection{Manufacturer's Profit Maximization Problem}

Now assume the manufacturer offers an MRP so that, for a fee, a customer is assured of the right to buy anti-viral drugs at the standard price of $p$ in the event of a pandemic. ${ }^{8}$ Let $R$ denote the number of MRP contracts sold. $R$ is constrained not to exceed $K$ since a manufacturer is obligated to have on hand supply to meet all MRP contracts. However, in the event of a pandemic, we are going to allow the manufacturer to sell unused MRP supply. That is, if some consumers with an MRP contract choose not to exercise the option and, at the same time, there is unmet demand from consumers without an MRP contract, then the company is permitted to sell the unused MRP supply to non-MRP consumers. This assumption seems realistic since, if there was excess demand for anti-viral drugs during a pandemic, it is difficult to believe that a drug manufacturer would be allowed to sit on supply. ${ }^{9}$

In characterizing the optimal number of MRP contracts and optimal supply, first note that the manufacturer can always set $R=0$, produce $K^{*}$, and achieve the same solution without the availability of the MRP. Thus, if the unique optimal value of $R$ is positive then the manufacturer prefers to offer an MRP to not doing so.

In solving the manufacturer's problem, the first step is to determine the equilibrium price of an MRP. It depends on the manufacturer's supply and how many MRP contracts are offered by the manufacturer (that is, how much supply it commits to its MRP). Given $R$ and $K$, we need to determine the maximum willingness to pay for an MRP contract. For a pandemic of size $\widetilde{q}$, the fraction of those impacted consumers who have an MRP contract is $R$, as the likelihood of needing the drug is independent of whether one has a contract. ${ }^{10}$ As the size of demand from those with MRP contracts is then $\widetilde{q} R$, the available supply after meeting MRP obligations is $K-\widetilde{q} R$. Given pandemic demand of $(1-R) \widetilde{q}$ from those without an MRP contract, all of them are supplied if and only if

$$
K-\widetilde{q} R \geq(1-R) \widetilde{q} \Leftrightarrow \widetilde{q} \leq K .
$$

If instead $\widetilde{q}>K$ then demand from those without an MRP contract exceeds the available supply. In that case, each non-MRP consumer demanding the drug is assumed to have an equal chance of obtaining the drug, which means a probability of

$$
\frac{K-\widetilde{q} R}{(1-R) \widetilde{q}}
$$

The expected net surplus for a non-MRP consumer is then

$$
(\bar{v}-p) \alpha\left[\int_{0}^{K} \widetilde{q} d F(\widetilde{q})+\int_{K}^{1} \widetilde{q}\left(\frac{K-\widetilde{q} R}{(1-R) \widetilde{q}}\right) d F(\widetilde{q})\right]
$$

\footnotetext{
${ }^{8}$ If it had bought into an MRP, a consumer could buy the drug even if there was no pandemic though, in this model, the MRP's value only arises with the occurence of pandemic influenza.

${ }^{9}$ In any case, we do not believe our results are sensitive to this assumption.

${ }^{10}$ In a richer model with consumer heterogeneity in terms of the risk of exposure to influenza, those consumers with the highest ex ante probability of exposure would presumably be most likely to buy into an MRP.
} 
or

$$
(\bar{v}-p) \alpha\left[\int_{0}^{K} \widetilde{q} d F(\widetilde{q})+\int_{K}^{1}\left(\frac{K-\widetilde{q} R}{1-R}\right) d F(\widetilde{q})\right]
$$

To explain this expression, recall that the surplus from buying the drug during a pandemic is $\bar{v}-p$, as its value to a consumer is $\bar{v}$ and the price is $p$. When $\widetilde{q} \leq K$, a non-MRP consumer gets the drug for sure, while if $\widetilde{q}>K$ then the probability of needing it and being able to buy it is $\frac{K-\widetilde{q} R}{1-R}$.

For a consumer with an MRP contract, her expected surplus is

$$
(\bar{v}-p) \alpha \int_{0}^{1} \widetilde{q} d F(\widetilde{q})
$$

With probability $\alpha \int_{0}^{1} \widetilde{q} d F(\widetilde{q})$, she is affected by pandemic influenza in which case she buys the drug and realizes a net surplus of $\bar{v}-p$. Thus, the maximum willingness to pay for an MRP is (4) minus (3). After some simplification, it equals:

$$
P^{m r p}(R, K) \equiv(\bar{v}-p) \alpha \int_{K}^{1}\left(\frac{\widetilde{q}-K}{1-R}\right) d F(\widetilde{q}) .
$$

Having decided to produce $K$ units of the drug and sell $R$ MRP contracts, the manufacturer will optimally price an MRP contract at $P^{m r p}$. Given total supply of $K$, note that the price of an MRP contract is increasing in the supply of MRP contracts:

$$
\frac{\partial P^{m r p}(R, K)}{\partial R}=(\bar{v}-p) \alpha \int_{K}^{1}\left(\frac{\widetilde{q}-K}{(1-R)^{2}}\right) d F(\widetilde{q})>0
$$

Given there is a pandemic, expected available supply for those consumers without an MRP contract is

$$
\int_{0}^{1}(K-\widetilde{q} R) d F(\widetilde{q})
$$

which is decreasing in $R$. Thus, as more MRP contracts are offered, those without a contract are more likely not to be supplied in the event of a pandemic which raises how much they are willing to pay to buy into an MRP.

The manufacturer's problem is:

$$
\max _{K, R} R(\bar{v}-p) \alpha \int_{K}^{1}\left(\frac{\widetilde{q}-K}{1-R}\right) d F(\widetilde{q})+\alpha p\left[\int_{0}^{K} \widetilde{q} d F(\widetilde{q})+\int_{K}^{1} K d F(\widetilde{q})\right]-c K
$$

subject to

$$
R \leq K
$$

The first term in (6) is the profit from selling MRP contracts, and the second term is the expected profit from selling the drug when there is a pandemic. Taking the derivative of the objective in (6) with respect to $R$ and simplifying, we have:

$$
\frac{\partial \cdot}{\partial R}=(\bar{v}-p) \alpha \int_{K}^{1}\left(\frac{\widetilde{q}-K}{(1-R)^{2}}\right) d F(\widetilde{q})>0
$$


Expected profit is then strictly increasing in the number of MRP contracts. Not only does a manufacturer want to offer an MRP but it commits all supply to the MRP. That the manufacturer chooses to offer an MRP is not surprising because it allows additional extraction of the surplus from selling an anti-viral drug in the event of a pandemic. By having to only pay a price of $p$, a consumer is left with surplus of $\bar{v}-p$. An MRP extracts some of that surplus by selling the right to buy the drug in the event of a pandemic. Below we explore how effectively an MRP extracts post-pandemic surplus. ${ }^{11}$

As it follows from (7) that $R=K$, the manufacturer's problem is

$$
\max _{K} K(\bar{v}-p) \alpha \int_{K}^{1}\left(\frac{\widetilde{q}-K}{1-K}\right) d F(\widetilde{q})+\alpha p\left[\int_{0}^{K} \widetilde{q} d F(\widetilde{q})+\int_{K}^{1} K d F(\widetilde{q})\right]-c K,
$$

and the FOC is

$$
\begin{aligned}
0= & (\bar{v}-p) \alpha \int_{K^{m r p}}^{1}\left(\frac{\widetilde{q}-K^{m r p}}{1-K^{m r p}}\right) d F(\widetilde{q}) \\
& -K^{m r p}(\bar{v}-p) \alpha \int_{K^{m r p}}^{1}\left(\frac{1-\widetilde{q}}{\left(1-K^{m r p}\right)^{2}}\right) d F(\widetilde{q})+\alpha p\left[1-F\left(K^{m r p}\right)\right]-c,
\end{aligned}
$$

where $K^{m r p}$ denotes optimal supply with an MRP. Taking the second derivative and simplifying, we see that the second-order condition is satisfied:

$$
-2(\bar{v}-p) \alpha\left(\frac{2-K}{(1-K)^{3}}\right) \int_{K}^{1}(1-\widetilde{q}) d F(\widetilde{q})-\alpha p F^{\prime}(K)<0 .
$$

\subsection{The Extent of Surplus Extraction by a Manufacturer Reserve Program}

To investigate how well an MRP extracts surplus, consider the incremental gain from being able to raise price to $\bar{v}$ when there is a pandemic, over and above that from having an MRP and being constrained to keeping price fixed at the pre-pandemic level of $p$. This gain equals (2) less (8) or

$$
\alpha(\bar{v}-p)\left\{\int_{0}^{K} \widetilde{q} d F(\widetilde{q})+K \int_{K}^{1}\left(\frac{1-\widetilde{q}}{1-K}\right) d F(\widetilde{q})\right\}>0 .
$$

Surplus extraction through an MRP is then incomplete. One reason is that, with an MRP, consumers are only willing to pay for access to supply when there is a shortage. Hence, in expectation, they are not willing to pay for access when $\widetilde{q}<K$ for, in that situation, they would be able to buy the drug at $p$ without having an MRP contract. However, if the manufacturer could adjust the price of its drug, it would charge a price of $\bar{v}$. Thus, when there is ample supply (that is, $\widetilde{q}<K$ ), the expected gain

\footnotetext{
${ }^{11}$ Of course, in practice, drug manufacturers do not only sell through an MRP. If we modelled demand for seasonal flu then the manufacturer would meet that demand outside of an MRP and thus would engage in both MRP sales and non-MRP sales. Whether this source of demand adequately explains non-MRP sales is admittedly an open question.
} 
in expected profit from being able to raise price - relative to keeping price fixed and having an MRP - is

$$
\alpha(\bar{v}-p) \int_{0}^{K} \widetilde{q} d F(\widetilde{q})
$$

this is the first term in (10).

The second reason for incomplete surplus extraction is associated with when the pandemic does exhaust supply, $\widetilde{q}>K$. When price can be increased, those consumers who need the drug are the ones who buy it, and, as a result, each pays $\bar{v}$ which generates total revenue of $\bar{v} K$ for the manufacturer. Who gets to buy scarce supply is then determined after consumers learn whether or not they need the drug. With an MRP, each of the consumers with an MRP contract only expects to exercise the buy option with some probability when there is a pandemic; specifically, the probability is $\widetilde{q}$ when the pandemic size is $\widetilde{q}$. Their willingness to pay for an MRP is then determined by the increase in the probability that they can acquire the good, when they need it. When $\widetilde{q}>K$, the probability a consumers needs it and gets when they don't have an MRP contract is

$$
\int_{K}^{1}\left(\frac{K-\widetilde{q} K}{1-K}\right) d F(\widetilde{q})
$$

and for when they do have an MRP contract is

$$
\int_{K}^{1} \widetilde{q} d F(\widetilde{q})
$$

The difference in these probabilities is

$$
\int_{K}^{1}\left(\frac{\widetilde{q}-K}{1-K}\right) d F(\widetilde{q})
$$

in which case buyers are willing to pay

$$
\alpha(\bar{v}-p) \int_{K}^{1}\left(\frac{\widetilde{q}-K}{1-K}\right) d F(\widetilde{q})
$$

for an MRP contract. In the event that there is a shortage, the revenue produced for the manufacturer is then

$$
\alpha(\bar{v}-p) \int_{K}^{1}\left(\frac{\widetilde{q}-K}{1-K}\right) d F(\widetilde{q})+\alpha p K[1-F(K)] .
$$

In contrast, the ex post willingness to pay for the $K$ units is

$$
\bar{v} K[1-F(K)],
$$

which is also the revenue earned when the manufacturer can raise its price. The difference between (12) and (11) is

$$
\alpha(\bar{v}-p) \int_{K}^{1}\left(\frac{1-\widetilde{q}}{1-K}\right) d F(\widetilde{q})
$$


which is the second term in (10). In summary, this surplus remains with the consumer because, with an MRP, the manufacturer extracts surplus prior to consumers learning who will need the drug in the event of a pandemic. When it can adjust the price of the drug ex post, the manufacturer is extracting surplus after consumers have learned who needs the drug. The latter produces full extraction, while the former does not.

Constrained in the price it can charge for its anti-viral drug, a drug manufacturer is unable to extract all of the surplus created by its drug when there is pandemic influenza. Through an MRP, it is able to claim some but not all of that residual surplus by selling the right to buy in the event of a pandemic. The reason for incomplete surplus extraction is that a consumer is ex ante uncertain that she would need to exercise the option to buy when there is pandemic influenza. If the pandemic is mild so there is no shortage of anti-viral drugs or if a consumer is not infected or exposed and thereby does not need the drug, no value is attached to owning an MRP contract. These events then reduce how much surplus a manufacturer can extract through the ex ante sale of the right to buy through an MRP.

\subsection{Impact of a Manufacturer Reserve Program on Stockpiling}

A central question to ask from a policy perspective is: Does the introduction of a Manufacturer Reserve Program increase the amount of anti-viral drugs available for pandemic influenza? Within the context of our model, the question is whether supply is higher when $R$ is set to maximize the manufacturer's expected profit compared to when there is no MRP (so that $R=0$ ). We explore that question in this section.

Let $\widehat{\pi}(K)$ denote expected profit when there is no MRP:

$$
\widehat{\pi}(K) \equiv \alpha p\left[\int_{0}^{K} \widetilde{q} d F(\widetilde{q})+\int_{K}^{1} K d F(\widetilde{q})\right]-c K .
$$

Expected profit with an MRP can then be represented as

$$
\widehat{\pi}(K)+K(\bar{v}-p) \alpha \int_{K}^{1}\left(\frac{\widetilde{q}-K}{1-K}\right) d F(\widetilde{q}),
$$

where the second term is revenue from selling MRP contracts. Consider the first derivative of (13):

$$
\widehat{\pi}^{\prime}(K)+(\bar{v}-p) \alpha \int_{K}^{1}\left(\frac{\widetilde{q}-K}{1-K}\right) d F(\widetilde{q})-K(\bar{v}-p) \alpha \int_{K}^{1}\left(\frac{1-\widetilde{q}}{(1-K)^{2}}\right) d F(\widetilde{q}) .
$$

Since (13) is strictly concave, supply is higher with an MRP if and only if expected profit (with an MRP) is increasing when evaluated at optimal supply without an MRP. Evaluating (14) at $K=K^{*}$, this is the case when

$$
(\bar{v}-p) \alpha \int_{K^{*}}^{1}\left(\frac{\widetilde{q}-K^{*}}{1-K^{*}}\right) d F(\widetilde{q})-K^{*}(\bar{v}-p) \alpha \int_{K^{*}}^{1}\left(\frac{1-\widetilde{q}}{\left(1-K^{*}\right)^{2}}\right) d F(\widetilde{q})>0 ;
$$

and this inequality can be shown to be equivalent to:

$$
\frac{\int_{K}^{1} \widetilde{q} d F(\widetilde{q})}{K^{*}\left(2-K^{*}\right)\left[1-F\left(K^{*}\right)\right]}>1
$$


Let us consider the extreme cases when the marginal cost of drug production is low and is high. In evaluating (15), recall that

$$
K^{*}=F^{-1}\left(\frac{\alpha p-c}{\alpha p}\right) .
$$

Suppose the cost of drug production is sufficiently high so that $c$ is close to $\alpha p$; that is, per unit cost is close to the expected revenue per unit without an MRP. Since

$$
\lim _{c \rightarrow \alpha p} K^{*}=0,
$$

we then want to evaluate $(15)$ as $K \rightarrow 0$ :

$$
\lim _{K \rightarrow 0} \frac{\int_{K}^{1} \widetilde{q} d F(\widetilde{q})}{K(2-K)[1-F(K)]}=\lim _{K \rightarrow 0} \frac{\int_{0}^{1} \widetilde{q} d F(\widetilde{q})}{K(2-K)[1-F(K)]}=+\infty .
$$

Thus, for $c$ close to $\alpha p$,

$$
0 \simeq K^{*}<K^{m r p} .
$$

Without an MRP, the expected revenue from producing to inventory is $\alpha p$ which is the probability of a pandemic times price. ${ }^{12}$ As cost approaches $\alpha p$, the optimal supply goes to zero because expected per unit profit goes to zero. Because an MRP enhances the ability of the manufacturer to extract surplus, the expected revenue from producing a unit to inventory is higher and equal to

$$
\alpha p+(\bar{v}-p) \alpha \int_{K}^{1}\left(\frac{\widetilde{q}-K}{1-K}\right) d F(\widetilde{q}) .
$$

Thus, even when $c$ is close to $\alpha p$, expected net profit is bounded above zero. As a result, the manufacturer produces more with an MRP. In fact, when $c=\alpha p$, the manufacturer has no pandemic inventory without an MRP, while it has a positive inventory with an MRP.

Now suppose marginal cost is very low so that optimal supply without an MRP is close to one (there are then enough drugs for the entire population):

$$
\lim _{c \rightarrow 0} K^{*}=1 .
$$

Using l'Hôpital's rule, evaluate (15) as $K \rightarrow 1$,

$$
\lim _{K \rightarrow 1} \frac{\int_{K}^{1} \widetilde{q} d F(\widetilde{q})}{K(2-K)[1-F(K)]}=\lim _{K \rightarrow 1} \frac{-K F^{\prime}(K)}{2(1-K)[1-F(K)]-K(2-K) F^{\prime}(K)}=-1 .
$$

Thus, for $c$ close to zero,

$$
1 \simeq K^{*}>K^{m r p}
$$

\footnotetext{
${ }^{12}$ Actually, that is expected revenue when the manufacturer can be assured of selling the good in the event of a pandemic, which is the case if its inventory is close to zero.
} 
When the cost of producing anti-viral drugs is very low, a manufacturer without an MRP produces close to maximal pandemic demand in order to be able to meet all levels of pandemic demand. However, with an MRP, it restricts supply in order to create a possible shortage which, in anticipation of, results in consumers willing to pay a higher price for an MRP contract. Note that as $K \rightarrow 1$, the value of an MRP goes to zero since there is sure to be sufficient supply even if there is pandemic influenza. ${ }^{13}$ The preceding results are summarized in Proposition 1.

Proposition 1 The manufacturer's pandemic inventory is higher (lower) with a Manufacturer Reserve Program when cost is sufficiently close to ap (zero).

To understand why stockpiling can be less with an MRP, consider the case when $c=0$ so that, in the absence of an MRP, the manufacturer produces enough drugs to meet the maximal pandemic size of 1 . Now introduce an MRP. With an inventory of size 1 , the value of an MRP contract is zero; ${ }^{14}$ since there will always be an adequate supply of anti-viral drugs then no consumer would buy an option to purchase. Thus, the expected revenue (and profit) of the manufacturer is that from pandemic sales of the drug:

$$
p \alpha \int_{0}^{1} \widetilde{q} d F(\widetilde{q}) .
$$

Now suppose the manufacturer reduces supply by a small amount $\varepsilon$. This supply reduction lowers expected drug sales by

$$
p \alpha \int_{1-\varepsilon}^{1}[\widetilde{q}-(1-\varepsilon)] d F(\widetilde{q}) \simeq p \alpha(\varepsilon / 2)[1-F(1-\varepsilon)] .
$$

If the pandemic size exceeds $1-\varepsilon$, it no longer has the supply to meet that additional demand. Note that revenue is reduced on the order of $\varepsilon^{2}$; that is, with a small probability, pandemic drug sales are reduced by a small amount. That same reduction in supply causes a rise in revenue from the sale of MRP contracts equal to

$$
\begin{aligned}
(1-\varepsilon) P^{m r p}(1-\varepsilon) & =(1-\varepsilon)(\bar{v}-p) \alpha \int_{1-\varepsilon}^{1}\left(\frac{\widetilde{q}-(1-\varepsilon)}{1-(1-\varepsilon)}\right) d F(\widetilde{q}) \\
& \simeq(\bar{v}-p) \alpha\left(\frac{1-\varepsilon}{2}\right)[1-F(1-\varepsilon)]
\end{aligned}
$$

\footnotetext{
${ }^{13}$ Setting $R=K$, the market price of an MRP contract is

$$
P^{m r p}(K, K) \equiv P^{m r p}(K)=(\bar{v}-p) \alpha \int_{K}^{1}\left(\frac{\widetilde{q}-K}{1-K}\right) d F(\widetilde{q}) .
$$

Since

$$
P^{m r p}(K) \leq(\bar{v}-p) \alpha \int_{K}^{1}\left(\frac{1-K}{1-K}\right) d F(\widetilde{q})=(\bar{v}-p) \alpha[1-F(K)]
$$

then

which implies

$$
\lim _{K \rightarrow 1} P^{m r p}(K) \leq \lim _{K \rightarrow 1}(\bar{v}-p) \alpha[1-F(K)]=0
$$

$$
\lim _{K \rightarrow 1} P^{m r p}(K)=0 .
$$

${ }^{14}$ This property is proven in footnote 12 .
} 
where $P^{m r p}(K)$ is the price of an MRP contract when supply is $K$ (and is exclusively sold through an MRP), and recall that $P^{m r p}(1)=0$. By reducing its supply by $\varepsilon$, a manufacturer's revenue from selling MRP contracts increases on the order of $\varepsilon$ which exceeds the fall in pandemic drug sales as it is on the order of $\varepsilon^{2}$. Thus, revenue and profit rise with this supply reduction.

On a more intuitive level, when a manufacturer would have a large stockpile (as is the case when $c$ is small), it'll be selling a large number of MRP contracts as stockpiling is done through an MRP. By restricting supply, it makes having an MRP contract more valuable since it is more likely that a consumer will need the drug. This rise in price results in surplus extraction from every consumer buying an MRP contract. While the smaller supply could mean smaller drug sales when there is a pandemic, that is a small revenue loss which occurs only when the size of the pandemic is large, which is a low probability event.

More precise results can be derived when the breadth of pandemic influenza is uniformly distributed. Assuming $F(\widetilde{q})=\widetilde{q}, \forall \widetilde{q} \in[0,1]$, optimal supply without an $\mathrm{MRP}$ is

$$
K^{*}=\frac{\alpha p-c}{\alpha p} .
$$

Solving (9) yields the optimal supply with an MRP:

$$
K^{m r p}=\frac{\alpha(\bar{v}+p)-2 c}{2 \alpha \bar{v}} .
$$

We then have:

$$
K^{*}-K^{m r p}=\left(\frac{\alpha p-c}{\alpha p}\right)-\left(\frac{\alpha(\bar{v}+p)-2 c}{2 \alpha \bar{v}}\right) ;
$$

and it is straightforward to show:

$$
\operatorname{sign}\left\{K^{*}-K^{m r p}\right\}=\operatorname{sign}\{\alpha p-2 c\} .
$$

Proposition 2 Assume $F$ is a uniform distribution on [0,1]. The manufacturer's pandemic inventory is higher (lower) with a Manufacturer Reserve Program when $c>(<) \frac{\alpha p}{2}$.

If marginal production cost is sufficiently small relative to price $p$ (or expected revenue $\alpha p$ ) then the introduction of an MRP reduces a drug company's pre-pandemic inventory of anti-viral drugs. For the case when cost is not relatively small, an MRP promotes the expansion of stockpiling. This raises the question of when these two cases might occur. Subsidies which lower a manufacturer's cost make it more likely that $c$ is small and thus more likely that an MRP would reduce pre-pandemic supply. Price caps - by lowering $p$ - have an opposite and, therefore, an MRP induces an expansion in supply. We can also interpret these results in terms of regulation of the price-cost margin. Suppose the price-cost margin is required not to exceed $r$ and that it is binding so that a drug manufacturer sets price so that:

$$
\frac{p-c}{c}=r \text { or } p=c(1+r) \text {. }
$$


Hence,

$$
\frac{\alpha p}{2}-c=\frac{\alpha c(1+r)}{2}-c=\frac{\alpha c}{2}\left(r-\frac{2-\alpha}{\alpha}\right) .
$$

It follows from the previous proposition that more stringent price-cost regulation smaller $r$ - makes it more likely the environment is one in which an MRP would promote stockpiling.

These results were derived under some strong simplifying assumptions about consumer demand, none of which we feel are necessary for the delivered insight. If consumers are risk averse then this would enhance the value of a customer having the option to buy anti-viral drugs, and thus increase the price that could be charged for an MRP contract. This greater demand for an MRP should only increase the desire of the drug manufacturer to, under certain conditions, limit supply in order to drive up the price of an MRP contract. A second factor one might want to allow for is insurance in connection with pharmaceutical products. Suppose now that a consumer's co-pay is $\theta p$, where $\theta \in(0,1)$, and $p$ continues to be the price charged by the drug manufacturer. Now, a consumer is willing to buy the drug during a pandemic as long as $p \leq v / \theta$. The manufacturer may then charge a higher price which makes it more likely that $p$ is high relative to $c$ and thus, by our preceding analysis, that an MRP will induce smaller supply. At the same time, that a consumer only pays part of the drug price means there is more surplus associated with getting the drug so a consumer is willing to pay a higher price for an MRP contract. ${ }^{15}$ As a third and final point concerning robustness, the model has only allowed for one consumer type. The analysis will clearly be more complicated with heterogeneous consumers but again the same type of manufacturer incentives ought to exist. What drives our results is that there is some probability that the pandemic size will exceed available supply so that there is excess demand. That property should occur as well when consumers are heterogenous. It is the prospect of a shortage that determines the price of an MRP contract and makes an MRP a critical source of revenue for the manufacturer. There is no reason to think that it would not be the case that the manufacturer would find it optimal to limit supply under an MRP in order to raise the price of an MRP contract.

\section{Concluding Remarks}

One of the measures that society can take to prepare for pandemic influenza is to stockpile anti-viral drugs which, in the event of a pandemic, can be taken prophylactically to avoid infection or for treatment in the event of infection. While the U.S. government has built a significant stockpile of anti-viral drugs, non-government organizations such as hospitals have been hesitant to do so, presumably because of the high cost of purchasing anti-viral drugs. To make stockpiling more attractive, drug manufacturers have developed Manufacturer Reserve Programs which, for an annual fee, ensures the right to buy anti-viral drugs. With an MRP, it is the drug

\footnotetext{
${ }^{15}$ Insurance may not be that relevant since MRP contracts are largely purchased by organizations - such as hospitals and corporations - who may be self-insuring.
} 
manufacturer that stockpiles in order to supply those consumers which have an MRP contract and then exercise the right to buy.

In this paper, we have shown that an MRP enhances drug manufacturer profit by allowing it to extract a bigger share of the surplus created by anti-viral drugs when there is a severe outbreak of influenza. An MRP allows a drug manufacturer to partly - though not fully - circumvent the political and ethical constraints of not being able to fully raise the price of its anti-viral drug in response to pandemic influenza. While an MRP enhances drug manufacturer profit, it may or may not serve the social goal of promoting pre-pandemic stockpiling. If the cost of producing an anti-viral drug is sufficiently high then - by augmenting the revenue earned from production - an MRP increases the optimal supply of a drug manufacturer relative to when no such program is offered. However, when production cost is sufficiently low, introducing an MRP reduces the amount of pre-pandemic stockpiling. Since the value of buying into an MRP is higher when the likelihood of a pandemic-induced shortage is greater, the drug manufacturer limits its inventory in order to create an anticipated shortage and thereby increase the price that consumers are willing to pay for the right to buy in the event of a pandemic. The gain in revenue from MRP contracts is realized on every contract sold, while the loss in revenue from having smaller pandemic drug sales (due to lower supply) only occurs when there is a shortage. When such a shortage is unlikely - which is the case when pre-pandemic supply (without an MRP) is large - then an MRP reduces supply; while if such a shortage is likely - which is the case when pre-pandemic supply (without an MRP) is low - then an MRP enhances supply. In short, Manufacturer Reserve Programs could either hurt or help in preventing the spread of pandemic influenza, and which is the case must be carefully evaluated.

\section{References}

[1] Courty, Pascal and Hao Li, "Sequential Screening," Review of Economic Studies, 67 (2000), 697-717.

[2] Dana, James D., Jr., "Advance-Purchase Discounts and Price Discrimination in Competitive Markets," Journal of Political Economy, 106 (1998), 395-422.

[3] Dana, James D., Jr., "Equilibrium Price Dispersion under Demand Uncertainty: The Roles of Costly Capacity and Market Structure," RAND Journal of Economics, 30 (1999), 632-660.

[4] Gale, Ian L. and Thomas J. Holmes, "The Efficiency of Advance-Purchase Discounts in the Presence of Aggregate Demand Uncertainty," International Journal of Industrial Organization, 10 (1992), 413-437.

[5] Gale, Ian L. and Thomas J. Holmes, "Advance-Purchase Discounts and Monopoly Allocation of Capacity," American Economic Review, 83 (1993), 135-146.

[6] Nocke, Volker and Martin Pietz, "Monopoly Pricing under Demand Uncertainty: The Optimality of Clearance Sales," Economic Journal, 117 (2007), 964-990. 
[7] Stole, Lars, "Price Discrimination and Competition," in Handbook of Industrial Organization, Volume III, M. Armstrong and R. Porter, eds., Amsterdam: NorthHolland, 2007. 